\title{
Leadership in anaesthesia teams: the most effective leadership is shared
}

\author{
Barbara Künzle, ${ }^{1}$ Enikö Zala-Mezö, ${ }^{2}$ Johannes Wacker, ${ }^{3}$ Michaela Kolbe, ${ }^{1}$ \\ Donat R Spahn, ${ }^{3}$ Gudela Grote ${ }^{1}$
}

${ }^{1}$ ETH Zurich, Department of Management, Technology, and Economics, Zurich, Switzerland ${ }^{2}$ Zurich University of Applied Sciences, Department of Research and Development Zurich, Switzerland

${ }^{3}$ University Hospital Zurich, Institute of Anaesthesiology, Zurich, Switzerland

\section{Correspondence to}

Dr Barbara Künzle, ETH Zurich, Department of Management, Technology, and Economics, Kreuzplatz 5, CH-8032 Zurich, Switzerland;

b.kuenzle@alumni.ethz.ch

Accepted 27 January 2010 Published Online First 14 May 2010

\section{ABSTRACT \\ Background Leadership plays a crucial role in teams working in complex environments, and research has shown that shared leadership where all team members perform leadership functions is an effective strategy. The authors aimed to describe shared leadership patterns during anaesthesia induction and show how they are linked to team performance.}

Methods 12 anaesthesia teams consisting of one resident and one nurse during a simulated anaesthesia induction including a non-routine event (asystole) were videotaped, and two kinds of leadership behaviour (content-oriented and structuring) were coded. Team performance was operationalised as the reaction time to the non-routine event. The amount of leadership sharedness was compared between low- and highperforming teams by performing a univariate analysis of variance. Wilcoxon signed-rank tests were used to analyse the distribution of the two kinds of leadership behaviour among team members.

Results Statistical analysis revealed that in highperforming teams, residents and nurses shared their leadership, while in low-performing teams, residents showed significantly higher levels of leadership behaviour than nurses. Further analyses revealed different distributions of leadership functions among team members. While residents of low-performing teams assumed both kinds of leadership behaviour, members of high-performing teams seemed to have distinct leadership roles: nurses mainly used content-oriented leadership behaviour, and residents tended to show structuring leadership behaviour.

Conclusions The study documents the effectiveness of shared leadership in situations with high task complexity and indicates that a clear distribution of content-oriented and structuring leadership among team members is an effective strategy. The findings have implications for training in shared leadership and also give rise to a number of recommendations for further research. ClinicalTrials (http://www.clinicaltrials.gov) registration number is NCT00706108.

\section{BACKGROUND}

Working in the operating room (OR) presents many cognitive, social and system challenges, and teamwork is an essential functional component to manage the time-pressured, critical and rapidly changing tasks. ${ }^{1}{ }^{2}$ An ever-increasing number of studies acknowledge that maximising patient safety plus reducing medical errors depends not only upon technical expertise but also on how decisions are made, ${ }^{3-8}$ how relevant information is communicated and tasks are coordinated in various
OR teams ${ }^{7}$ 9 10-16 _abilities which are all categorised as non-technical skills. ${ }^{17}$ Out of the growing emphasis on effective team coordination in the $\mathrm{OR}$ a closer examination of leadership dynamics in critical care seems to be evident. This paper adopts previous research findings on shared leadership in OR teams ${ }^{18-23}$ in order to focus on shared leadership in anaesthesia teams and examine links between shared leadership behaviour and team effectiveness. Due to the extreme complexity and often large size of a typical OR team, we believe that focussing on two-person anaesthesia teams with their high technical and non-technical skill demands offers an ideal microcosm of the larger OR team that they are a part of and therefore may provide an important insight into medical critical care leadership demands and solutions.

We drew on two leadership perspectives that are particularly relevant to anaesthesia teams: (1) functional leadership and (2) shared leadership. The concept of functional leadership ${ }^{24}$ proposes that effective leaders assume specific leadership actions (eg, managing personnel and material resources) as required by the team and that leadership is fulfilled by formally as well as informally appointed leaders. Shared leadership builds on this flexibility and is defined as a 'a dynamic, interactive influence process among individuals in groups for which the objective is to lead one another to the achievement of group or

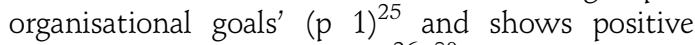
effects on team outcomes, ${ }^{26-30}$ notably also if interdependency and task complexity increase. ${ }^{31-33}$ Not surprisingly, shared leadership has been shown to be relevant for various OR teams. ${ }^{18} 2123$

Our study tested two hypotheses, both dealing with the distribution of leadership among team members. As anaesthesia is characterised by high task complexity, making great demands on leadership, ${ }^{34} 35$ we focus on how a non-routine event increases task load and its consequential influence on leadership distribution. According to the abovementioned correlation between task complexity and demands on leadership, we expected that with increased task load, a single leader might have difficulty fulfilling leadership functions due to the concurrent demands on their technical functions. Sharing leadership might therefore reduce task overload and increase team performance. We therefore propose the following hypothesis:

Hypothesis 1: High-performing teams have a higher degree of shared leadership than low-performing teams, specifically if task load is high.

In constructing the second hypothesis, we examined the functionally differentiated leadership 
requirements of anaesthesia teams in the current study, considering two different leadership factors found to be relevant in general $^{3637}$ and critical care medical teams specifically ${ }^{18} 203839$ : 1. Content-oriented leadership concentrates on the understanding of the task and on actual or potential challenges. Content-oriented leaders foster the processing of information, offering the grist for sense-making to team members by information search and exchange.

2. Structuring leadership is about guiding and structuring team processes by coordinating team activities such as role distribution and managing resources. ${ }^{24}$

Because these two leadership functions utilise different skills, it follows that team leadership is more effective when the appropriate style is distributed according to the respective skills of team members. ${ }^{40}$ Since the nurses of the anaesthesia teams we studied tended to have longer tenure within the same work unit, we assumed that they generally had more hospital work experience than the residents who often came directly from university. In the investigated intubation scenario where residents were responsible for administering intubation, we expected nurses to provide more content-oriented leadership and residents-as formal leaders focussing on the specific task-to perform more structuring leadership. We also expected these distinct leadership roles to be positively related to team performance. We proposed:

Hypothesis 2: In high-performing teams, residents take over the structuring leadership function, whereas nurses take over the content-oriented leadership function, especially if task load is high.

\section{METHODS}

\section{Setting}

We analysed 13 video recordings of anaesthesia teams who volunteered to perform simulated routine anaesthesia inductions in regular $\mathrm{OR}$ using a resuscitation mannequin for advanced live support allowing arrhythmia simulation (MegaCode, Laerdal).
Anaesthesia induction is the first step in all operations requiring general anaesthesia and was analysed because it offered the opportunity to study anaesthesia teams with minimal interference from others such as surgical and OR teams. To increase task load during induction, a cardiac arrest (asystole) was simulated in reaction to laryngoscopy as the non-routine event-defined as an unexpected, atypical event. ${ }^{41}$ Videos and vital parameter data were recorded using a setup allowing synchronised recording of video, monitor and ventilator data.

\section{Study participants}

All teams consisted of one anaesthesia resident (five females, eight males), one anaesthesia nurse (six females, seven males), with a male on call consultant anaesthetist immediately available if requested. Sample size was determined by availability of staff and team members who held at least 6 months' work experience in anaesthesia. Team composition and role distribution represented common practice of the tertiary teaching hospital where the study was conducted: the resident performed intubation while assisted by the nurse. Local institutional ethics committee approval was obtained, and participating staff gave their written informed consent. ${ }^{1}$

\section{Measures \\ Leadership behaviour}

The leadership taxonomy recorded two leadership behaviour categories: content-oriented and structuring leadership. Table 1 provides descriptions and examples of these categories. To check for inter-rater reliability of the behaviour codings, three trained raters independently coded a test sample of five cases out of 13 . The first coder divided the sample into coding units which were coded by the other two. A coding unit was one uttered statement, usually a phrase. A new unit started as soon as the speaker and/or the topic changed. The occurrence of leadership behaviour was recorded on the basis of verbalised team interactions. Kappa statistics revealed a very good inter-rater agreement for

Table 1 Samples of coded videotape segments

\begin{tabular}{|c|c|c|c|}
\hline Main category & Code & Observable behaviour & Example \\
\hline \multirow[t]{3}{*}{ Content-oriented leadership } & Information collection & $\begin{array}{l}\text { Team members proactively acquire task } \\
\text { relevant information }\end{array}$ & $\begin{array}{l}\text { 'Do we have Atropine on hand?' } \\
\text { 'Did you inject } 1 \% \text { solution?' }\end{array}$ \\
\hline & Information transfer & $\begin{array}{l}\text { Team members proactively provide task } \\
\text { relevant information or knowledge }\end{array}$ & $\begin{array}{l}\text { Information about the state of the } \\
\text { patient-for example, 'ventilating is } \\
\text { easy.' } \\
\text { Information about strategy or deci- } \\
\text { sions: 'Blood pressure measurement is } \\
\text { set to } 2 \text { min.' }\end{array}$ \\
\hline & Problem-solving & $\begin{array}{l}\text { Team members verbalise a problem, } \\
\text { provide interpretation of a problem, are } \\
\text { looking for a solution and are setting new } \\
\text { goals }\end{array}$ & $\begin{array}{l}\text { 'I'm not worried about the bradycar- } \\
\text { dia-that's due to the Fentanyl.' } \\
\text { 'Maybe this instrument is broken?' }\end{array}$ \\
\hline \multirow[t]{5}{*}{ Structuring leadership } & $\begin{array}{l}\text { Distribution of roles and } \\
\text { assigning tasks }\end{array}$ & $\begin{array}{l}\text { Team members assign tasks or roles to } \\
\text { other team members }\end{array}$ & $\begin{array}{l}\text { 'Please inject } 10 \mathrm{mg} \text { propofol"' } \\
\text { Could you hold the mask for me, } \\
\text { please?' }\end{array}$ \\
\hline & Decision about procedures & $\begin{array}{l}\text { Team members offer clear performance } \\
\text { strategies or show other team members } \\
\text { how to do something }\end{array}$ & $\begin{array}{l}\text { 'We're going to provide respiration } \\
\text { without a filter' } \\
\text { 'We prepare atropine but wait before } \\
\text { injecting' }\end{array}$ \\
\hline & Initiate an action & $\begin{array}{l}\text { Team members initiate an action without } \\
\text { being asked }\end{array}$ & $\begin{array}{l}\text { 'I'll start with the blood pressure } \\
\text { measurement' }\end{array}$ \\
\hline & Structuring work process & $\begin{array}{l}\text { Team members determine the sequence } \\
\text { of actions, coordinate pace and rhythm of } \\
\text { activities and plan next steps }\end{array}$ & $\begin{array}{l}\text { 'Let's wait until the frequency goes up, } \\
\text { then we'll try it again' } \\
\text { Nurse asks whether she is allowed to } \\
\text { preoxygenise the patient. Resident } \\
\text { answers: 'No, not yet. Let me first fill } \\
\text { out the report.' }\end{array}$ \\
\hline & Resource management & $\begin{array}{l}\text { Team members manage staff and } \\
\text { equipment resources }\end{array}$ & $\begin{array}{l}\text { Additional equipment or staff is } \\
\text { requested } \\
\text { - Somebody is asked to help }\end{array}$ \\
\hline
\end{tabular}


both structuring leadership $(\mathrm{K}=0.88)$ and content-oriented leadership ( $\mathrm{K}=0.76$ ).

Shared leadership is defined as 'a dynamic, interactive influence process among individuals in groups for which the objective is to lead one another (...)' (p 1), ${ }^{25}$ meaning the transference of leadership functions among team members where both formal and informal leaders exhibit leadership. Shared leadership was operationalised as the difference between the leadership behaviour levels of both team members: a high degree of sharedness meant both team members demonstrated similar amounts of leadership (mean rates per minute); a low degree meant one team member showed significantly more leadership than the other.

\section{Task load}

Emulating a previous study on coordination in anaesthesia teams, ${ }^{15}$ changes in leadership behaviour, including degree of sharedness, were analysed during work phases differing in the level of task load. Task load was described as an external indicator of objective load, including factors such as task demands and situational requirements. ${ }^{42}$ Levels of task load were drawn from 20 in-depth, one-on-one interviews with participating team members rating them on a scale from 1 to 10,10 being the highest value for high task load, and confirmed by an experienced staff anaesthetist. To control for variation in length of the three phases, raw data frequencies were transformed to rates per minute by dividing unit frequencies within a phase by duration of that phase (see table 2).

\section{Performance measures}

Team performance was measured as reaction time after simulated asystole during laryngoscopy (direct visualisation of vocal cords) for intubation of the trachea, an event that is infrequent enough to be considered non-routine but which, according to the literature, has a realistic likelihood of occurring. ${ }^{43-47}$ Applying the concept of reaction time measurement of a single provider $^{48-50}$ to a team, we measured the delay from the beginning of simulated asystole until simulated reinstallation of sinus rhythm when predefined actions consistent with ACLS guidelines were taken ('execution time') where speed of correct management was paramount to defining successful team performance. In the case of anaesthesia staff, advanced cardiac life support is a well-established part of their medical training, and a response according to ACLS guidelines can reasonably be expected from these teams. The speed of response to this timecritical event can therefore be taken as the performance measure for response to a non-routine, anaesthesia team event.

A box plot analysis identified one extreme outlier case (defined as more than three times the IOR than the upper quartile) with a reaction time of $124 \mathrm{~s}$. This instance was excluded in order to achieve statistically sound comparable team reaction times. ${ }^{51}$ The duration of execution time for the remaining 12 teams ranged between 10 and $53 \mathrm{~s}(\mathrm{M}=30.33 ; \mathrm{SD}=13.52)$. A median split of team performance was used to build two groups of performance (above the median=high-performing teams, below the median=low-performing teams).

\section{Control variables}

We controlled for team member anaesthesia work experience and for shared work experience by calculating Mann-Whitney tests. No differences were found between the low- and highperforming teams, $U_{\text {experience nurses }}=7, \mathrm{p}=0.09, \mathrm{r}=-0.53$, $U_{\text {experience residents }}=17.5, \mathrm{p}=0.94, \mathrm{r}=-0.24$ and $U_{\text {shared working }}$ experience $=10, \mathrm{p}=0.24, \mathrm{r}=-0.38$.

\section{Data analysis}

An extreme group analysis was applied comparing Phases 1 and 3 (low vs high task load; table 2, shaded columns). After visual inspection of data (Stem-and-leaf plots, box plots), we performed a logarithmic transformation to calculate a univariate analysis of variance (ANOVA) using the GLM procedure of SPSS used to test Hypothesis 1. To test Hypothesis 2, Wilcoxon signed-rank tests were performed.

\section{RESULTS}

Table 2 shows the descriptions, duration and levels of task load of the three work phases.

Hypothesis 1 proposed that high-performing teams have a higher degree of shared leadership than low-performing teams, especially if task load is high. Members of low-performing teams showed almost identical amounts of leadership during low task load indicating that leadership is shared, while residents showed twice as much leadership than nurses during high task load (figure 1). Univariate ANOVA revealed a significant effect of shared leadership, $F(1,20)=7.14 ; p<0.05, \eta_{p}^{2}=0.26$ but no significant interaction between task load and shared leadership $\mathrm{F}$ $(1,20)=1.41, p=0.25, \eta_{p}^{2}=0.07$, indicating that these differences were not dependent upon task load (table 3). In high-performing teams, nurses and residents were evenly engaged in leadership during low- and high-task-load situations (figure 1). ANOVA revealed no significant effect for shared leadership $F(1,20)=0.00$, $\mathrm{p}=0.97, \eta_{\mathrm{p}}^{2}=0.0$, indicating that leadership was equally distributed. The interaction between task load and shared leadership was not significant $F(1,20)=0.51, p=0.49, \eta_{p}^{2}=0.03$, suggesting that the distribution of leadership was not due to task load (table 3). Thus, Hypothesis 2 is only partially confirmed.

Hypothesis 2 proposed that in high-performing teams, residents take over the structuring leadership function, whereas nurses take over the content-oriented leadership function during

Table 2 Phases of simulated induction to general anaesthesia and respective level of task load

\begin{tabular}{|c|c|c|c|}
\hline & $\begin{array}{l}\text { Phase } 1 \\
\text { Preparation }\end{array}$ & $\begin{array}{l}\text { Phase } 2 \\
\text { Preintubation }\end{array}$ & $\begin{array}{l}\text { Phase } 3 \\
\text { Intubation including non-routine event }\end{array}$ \\
\hline Main tasks & $\begin{array}{l}\text { Preparation of material and } \\
\text { equipment }\end{array}$ & Administrations of drugs & $\begin{array}{l}\text { Induction of endotracheal tube } \\
\text { into trachea using laryngoscopy. } \\
\text { Asystoly is simulated. }\end{array}$ \\
\hline Behavioural marker for start time & $\begin{array}{l}\text { Team members enter the } \\
\text { operating room }\end{array}$ & $\begin{array}{l}\text { Decision to start medication is } \\
\text { made or the first drug is given }\end{array}$ & Decision to intubation is made \\
\hline Behavioural marker for end time & $\begin{array}{l}\text { Before decision to start medication is } \\
\text { made, or if no decision is made, before } \\
\text { the first drug is given }\end{array}$ & $\begin{array}{l}\text { Before decision to start intubation } \\
\text { is made }\end{array}$ & After the tube is fixed \\
\hline Mean duration in minutes & 7.71 & 5.77 & 0.62 \\
\hline Mean ratings of task load & 3.8 & 4.8 & 7.2 \\
\hline Level of task load & Low & Moderate & High \\
\hline
\end{tabular}


Figure 1 Distribution of contentoriented and structuring leadership among team members in high- and lowperforming teams during high- and lowtask-load situations. Note: The values represent mean rates of leadership behaviour per minute. $a, b n=12(6$ nurses, 6 residents).

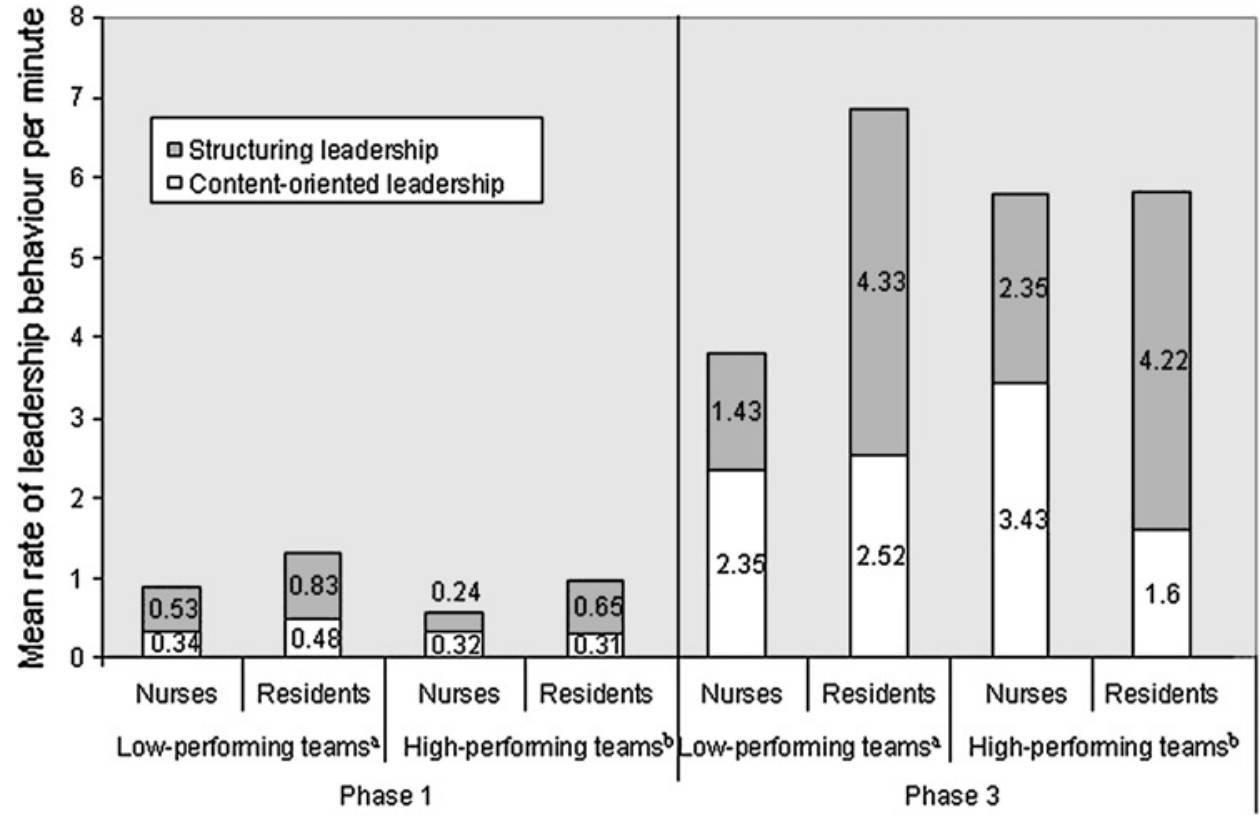

Phase 3 high task load. Results showed that nurses in high-performing teams demonstrated more content-oriented leadership behaviour compared with residents, $z=-0.734, p=0.46, r=-0.43$, while residents showed more structuring leadership than nurses, $z=-1.483, p=0.14, r=-0.21$, indicating distinct leadership roles, but these differences were not significant (figure 1). In lowperforming teams, residents showed more content-oriented leadership than nurses, $z=0.000, p=1, r=0$ as well as significantly more structuring leadership, $\mathrm{z}=-2.023, \mathrm{p}=0.04, \mathrm{r}=-0.58$, indicating that no distinct leadership roles exist (figure 1). Thus, Hypothesis 2 is only partially supported.

\section{DISCUSSION}

This study investigated leadership in anaesthesia teams operating in a simulated setting. The results provide some evidence for the appropriateness of sharing leadership in situations with high task load induced by a non-routine event, especially regarding the advantages of distributing leadership style according to skill set rather than formal leadership ranking. This is in line with other studies outside healthcare ${ }^{31} 32$ suggesting that shared leadership is especially effective if interdependency and task complexity are high. It is interesting to note, however, that those findings differ from results on leadership in other

Table 3 Results of univariate ANOVA for leadership distribution in lowand high-performing teams

\begin{tabular}{llrlll}
\hline Source & $\begin{array}{l}\text { Sum of } \\
\text { squares }\end{array}$ & df & $\mathbf{F}$ & $\mathbf{p ~ V a l u e ~}$ & $\eta_{\mathbf{p}}^{\mathbf{2}}$ \\
\hline Low-performing teams $\dagger$ & & & & & \\
Task load (T) & 1.25 & 1 & $58.57^{* * *}$ & 0.000 & 0.745 \\
Shared leadership (D) & 0.15 & 1 & $7.14^{*}$ & 0.015 & 0.263 \\
T $\times \mathrm{D}$ & 0.03 & 1 & 1.41 & 0.248 & 0.066 \\
Error & 0.43 & 20 & $(0.02)$ & & \\
High-performing teams $\dagger$ & & & & & \\
Task load (T) & 1.21 & 1 & $11.26^{* *}$ & 0.003 & 0.360 \\
Shared leadership (D) & 0.00 & 1 & 0.00 & 0.971 & 0.000 \\
T $\times \mathrm{D}$ & 0.05 & 1 & 0.51 & 0.485 & 0.025 \\
Error & 2.14 & 20 & $(0.11)$ & & \\
\hline
\end{tabular}

Values shown in parentheses represent mean square errors.

${ }^{*} \mathrm{p}<0.05 ;{ }^{* *} \mathrm{p}<0.01 ;{ }^{* * *} \mathrm{p}<0.001$.

$+\mathrm{n}=12$ ( 6 nurses, 6 residents). critical care teams, suggesting that the senior leader is more likely to assume the active leadership the more urgent the situation. $^{21}$ These differences, however, are conceivably due to the different team structures observed. While our study observed anaesthesia teams consisting of one nurse and one resident, the teams investigated by the other authors involved diver members of various professional groups.

The distribution of the leadership functions in our study showed that members of high-performing teams seem to utilise distinct leadership styles, especially in high-task-load situations. One could explain this by their respective functional responsibilities: residents intubated the patient and are consequently highly focused, making it necessary to directly guide and coordinate team activities. Due to their physical perspective, nurses have a comprehensive view of circumstances and are more likely to provide residents with task-relevant information. As residents of high-performing teams were more willing to share leadership functions with the nurses, this indicates that these residents acknowledge and can accept the medical know-how of nurses, who usually have more experience in clinical settings and, due to their tenure in that particular hospital, more knowledge of the resources available. Members of low-performing teams did not distribute the two leadership functions clearly among each other, conceivably indicating that residents were overloaded by trying to perform both technical and non-technical functions, while high-performing teams seem to take advantage of individual member strengths and transfer leadership functions accordingly among team members.

Our study also shows that team performance was influenced by strengths in non-technical skills, as differences in sharedness of leadership partly explain the performance of anaesthesia teams. This is in line with the increasing number of studies generally stressing the link between various non-technical skills and performance in OR teams. ${ }^{175253}$ Although the link is far from definitive in our study, results indicate that the utilisation of shared leadership is effective when a non-routine event occurs and that high-performing teams distribute leadership according to skill sets. In accordance with others, ${ }^{17} 54$ we emphasise the need for training in non-technical skills in order to maximise patient safety by being better able to manage OR challenges within this time-pressured, critical environment. 


\section{Limitations, implications for further research and practice}

A limitation of this study is that results are those of tandem teams in a simulated anaesthesia induction setting. We would therefore recommend broadening research on effective leadership strategies, particularly on shared leadership for anaesthesia and other medical teams. More research is needed to confirm whether the effectiveness of sharing leadership in high-task-load situations is a stable finding and also representative for other $\mathrm{OR}$ teams. In this study, team composition remained static during the whole task due to the simulated setting. Studies of anaesthesia teams would benefit from observing live settings where additional team members often join the team, most likely redistributing the leadership structure, which were observed to be positively related to team performance. ${ }^{18}$

We conclude that shared leadership within anaesthesia teams seems to facilitate performance in complex tasks given that no individual team member possesses all resources necessary to address all task demands and therefore appears to be an effective strategy to overcoming resource shortcomings-especially if task complexity is high. As complexity increases where an individual leader has difficulties completing all necessary leadership functions, distributing roles according to skill sets means that anaesthesia teams could handle non-routine events more effectively. Sharing leadership releases formal leaders from the pressure of being the singular source of influence by increasing the team's sources of effective leadership.

Funding This work was supported by the ETH Research Grant TH -10/05-1, Switzerland

\section{Competing interests None}

Ethics approval Ethics approval was provided by the institutional ethics committee, Gesundheitsdirektion Kanton Zurich, Ethik-Kommission (KEK), Zurich, Switzerland.

Contributors Note: the current study involves a reanalysis of the data presented by $\mathrm{BK}, \mathrm{EZ}-\mathrm{M}, \mathrm{MK}, \mathrm{JW}$ and GG. ${ }^{55}$

Provenance and peer review Not commissioned; externally peer reviewed.

\section{REFERENCES}

1. Baker DP, Gustafson S, Beaubien JM, et al. Medical team training programs in health care. Adv Patient Saf 2005:4:253-67.

2. Salas $\mathbf{E}$, Rosen MA, King $H$. Managing teams managing crises: principles of teamwork to improve patient safety in the emergency room and beyond. Theor Issues Ergon Sci 2007:8:381-94.

3. Bogner MS. Naturalistic decision making in health care. In: Zsambok CA, Klein G, eds Naturalistic decision making. Mahwah, NJ: Laurence Erlbaum Associates, 1997:61-9.

4. De Keyser V, Nyssen A-S. The management of temporal constraints in naturalistic decision making: the case of anesthesia. In: Salas E, Klein G, eds. Linking expertise and naturalistic decision making. Mahwah, NJ: Lawrence Erlbaum Associates, 1992: 171-88.

5. Flin R, Youngson G, Yule S. How do surgeons make intraoperative decisions? Qual Saf Health Care 2007:16:235-9.

6. Gaba DM, Howard SK, Fish KJ, et al. Simulation-based training in anesthesia crisis resource management (Acrm): a decade of experience. Simul Gaming 2001;32:175-93.

7. Lingard L, Espin S, Whyte $S$, et al. Communication failures in the operating room: an observational classification of recurrent types and effects. Qual Saf Health Care 2004; 13:330-4

8. Morineau T, Morandi X, Le Moellic N, et al. Decision making during preoperative surgical planning. Hum Factors: J Hum Factors Ergon Soc 2009;51:67-77

9. Catchpole K, Bell MDD, Johnson S. Safety on anaesthesia: a study of 12606 reported incidents from the UK National reporting and learning system. Anaesthesia 2008;63:340-6

10. Catchpole K, Mishra A, Handa A, et al. Teamwork and error in the operating room. Analysis of skills and roles. Ann Surg 2008;247:699-706.

11. Cooper JB, Newbower RS, Long CD, et al. Preventable anesthesia mishaps: a study of human factors. Qual Saf Health Care 2002:11:277-82.

12. Gaba DM. Anaesthesiology as a model for patient safety in health care. BMJ 2000;320:785-8.

13. Greenberg CC, Regenbogen SE, Studdert DM, et al. Patterns of communication breakdowns resulting in injury to surgical patients. J Am Coll Surg 2007;204:533-40.
14. Manser T, Howard SK, Gaba DM. Adaptive coordination in cardiac anaesthesia: a study of situational changes in coordination patterns using a new observation system. Ergonomics 2008;51:1153-78.

15. Zala-Mezö E, Wacker J, Künzle B, et al. The influence of standardisation and taskload on team coordination patterns during anaesthesia inductions. Qual Saf Health Care 2009:18:127-30.

16. Zingg U, Zala-Mezoe E, Kuenzle B, et al. Evaluation of critical incidents in general surgery. Br J Surg 2008;95:1420-5.

17. Flin R, Maran N. Identifying and training non-technical skills for teams in acute medicine. Qual Saf Health Care 2004;13:180-4.

18. Tschan F, Semmer NK, Gautschi D, et al. Leading to recovery: group performance and coordinative activities in medical emergency driven groups. Hum Perf 2006;19:277-304.

19. Künzle B, Kolbe M, Grote G. Ensuring patient safety through effective leadership behaviour: a literature review. Saf Sci. 2010:48:1-17.

20. Cooper S, Wakelam A. Leadership of resuscitation teams: 'lighthouse leadership.' Resuscitation 1999;42:27-45.

21. Klein KJ, Ziegert JC, Knight AP, et al. Dynamic delegation: shared, hierarchical, and deindividualized leadership in extreme action teams. Adm Sci 0 2006:51:590-621.

22. Yun S, Faraj S, Henry PS Jr. Contingent leadership and effectiveness of trauma resuscitation teams. J App/ Psychol 2005;90:1288-96.

23. Xiao Y, Seagull FJ, Mackenzie CF, et al. Adaptive leadership in trauma resuscitation teams: a grounded theory approach to video analysis. Cognit Tech Work 2004;6:158-64.

24. Zaccaro SJ, Rittman AL, Marks MA. Team leadership. Leadersh 0 2001:12:451-83

25. Pearce CL, Conger JA. All those years ago In: Pearce CL, Conger JA eds. Shared leadership: reframing the How's and Why's of leadership. Thousand Oaks, CA: Sage 2003:1-18.

26. Avolio BJ, Jung DI, Murry W, et al. Building highly developed teams: focusing on shared leadership process, efficacy, trust, and performance. In: Beyerlein MM, Johnson DA, Beyerlein ST, eds. Advances in interdisciplinary studies of work teams. team leadership. Greenwich, CT: JAI Press, 1996:173-209.

27. Hooker C, Csikszentmihalyai C. Flow, creativity and shared leadership: rethinking the motivation and structuring of knowledge work. In: Pearce CL, Conger JA, eds. Shared leadership: reframing the Hows and Whys of leadership. Thousand Oaks, CA: Sage 2003:217-34.

28. Shamir B, Lapidot Y. Shared leadership in the management of group boundaries: a study of expulsions from officers' training courses. In: Pearce CL, Conger JA, eds. Shared leadership: reframing the Hows and Whys of leadership. Thousand Oaks, CA Sage, 2003:235-49.

29. Pearce CL, Yoo Y, Alavi M. Leadership, social work and virtual teams: the relative influence of vertical versus shared leadership in the nonprofit sector. In: Riggio RE, Smith-Orr S, Shakely J, eds. Improving leadership in nonprofit organizations. San Francisco, CA: Jossey-Bass, 2004:180-204.

30. Ensley MD, Hmieleski KM, Pearce CL. The importance of vertical and shared leadership within new venture top management teams: implications for the performance of startups. Leadersh 0 2006;17:217-31.

31. Pearce CL. The future of leadership: combining vertical and shared leadership to transform knowledge work. Acad Manag Exec 2004;18:47-57.

32. Cox JF, Pearce CL, Perry ML. Toward a model of shared leadership and distributed influence in the innovation process. In: Pearce CL, Conger JA, eds. Shared leadership: reframing the How's and Why's of leadership. Thousand Oaks, CA: Sage, 2003: 48-76.

33. Mayo M, Meindl JR, Pastor J-C. Shared leadership in work teams. In: Pearce CL, Conger JA, eds. Shared leadership: reframing the How's and Why's of leadership. Thousand Oaks, CA: Sage, 2003:193-214.

34. Kerr S, Jermier JM. Substitutes for leadership: their meaning and measurement. Organ Behav Hum Perform 1978;22:375-403

35. Kozlowski SW, Gully S, McHugh P, et al. A dynamic theory of leadership and team effectiveness: developmental and task contingent leader roles. In: Ferris G, ed Research in personnel and human resource management. Greenwich: CT: JAl, 1996:253-305.

36. Bales RF, Slater PE. Role differentiation in small decision-making groups. In: Parson T, Bales RF, eds. Family, socialization, and interaction process. Glencoe: The Free Press, 1955:259-306.

37. Stempfle J, Badke-Schaub P. Führungshandeln Im Alltag: Ein Modell Zur Analyse Von Führungsprozessen [Leaders at work: a model for the analysis of leadership processes]. Zeitschrift für Arbeits- und Organisationspsychologie 2005;49:92-101

38. Zala-Mezö E, Künzle B, Wacker J, et al. Zusammenarbeit in Anästhesieteams Aus Sicht Der Teammitglieder [Cooperation in anesthesia teams as seen by team members]. Zeitschrift für Arbeitswissenschaften 2004:58:199-207.

39. Marsch SCU, Müller C, Marquardt K, et al. Human factors affect the quality of cardiopulmonary resuscitation in simulated cardiac arrests. Resuscitation 2004;60:51-6.

40. Stempfle J, Hubner 0, Badke-Schaub P. A functional theory of task role distribution in work groups. Group Process Intergroup Relat 2001:4:138-59.

41. Weinger MB, Slagle J. Human factors research in anesthesia patient safety: techniques to elucidate factors affecting clinical task performance and decision making. J Am Med Inform Assoc 2002;9:58-63. 
42. Grote G, Zala-Mezö E, Grommes P. The effects of different forms of co-ordination on coping with workload. In: Dietrich R, Childress TM, eds. Group interaction in high risk environments. Aldershot: Ashgate, 2004:39-54.

43. Bricchi M, Gemma M. Asystole during anesthesia with propofol. Ann Fr Anesth Reanim 1991;10:492.

44. Guise PA. Asystole following propofol and fentanyl in an anxious patient. Anaesth Intensive Care 1991:19:116-18.

45. Russ MJ, Bailine SH. Asystole and bradycardia related to anesthetic induction during ECT: a case report. J ECT 2004;20:195-7.

46. Sutera PT, Smith CA. Asystole during laryngoscopy and tracheal intubation. $J$ Cardiothorac Vasc Anesth 1994:8:79-80.

47. Wang J, Winship S, Russell G. Induction of anaesthesia with sevoflurance and lowdose remifentanil: asystole following laryngoscopy. Br J Anaesth 1998;81:994-5.

48. DeAnda A, Gaba DM. Role of experience in the response to simulated critical incidents. Anesth Analg 1991;72:308-15.
49. Gaba DM, DeAnda A. The response of anesthesia trainees to simulated critical incidents. Anesth Analg 1989;68:444-51.

50. Weinger MB, Herndon OW, Zornow MH, et al. An objective methodology for task analysis and workload assessment in anesthesia providers. Anesthesiology 1994;80:77-92.

51. Tabachnick BG, Fidell LS. Using multivariate statistics. 5th edn. Boston, MA: Allyn and Bacon, 2007

52. Yule S, Flin R, Paterson-Brown S, et al. Non-technical skills for surgeons in the operating room: a review of the literature. Surgery 2006;139:140-9.

53. Reader T, Flin R, Lauche K, et al. Non-technical skills in the intensive care unit. $\mathrm{Br} \mathrm{J}$ Anaesth 2006;96:551-9.

54. Fletcher G, Flin R, McGeorge $\mathrm{P}$, et al. Anaesthetists' non-technical skills (ants): evaluation of a behavioural marker system. Br J Anaesth 2003;90:580-8.

55. Künzle B, Zala-Mezö E, Kolbe M. Substitutes for leadership in anaesthesia teams. Eur J Work Organ Psychol. In press. 